\title{
Influence of the composition of the oak bark extract and chlortetracycline on hematological blood parameters of broiler chickens
}

\author{
Olga Kvan ${ }^{1,2, *}$, Galimzhan Duskaev², Elena Sheida ${ }^{1,2}$, Shamil Rakhmatullin², and Dianna Kosyan ${ }^{2}$ \\ ${ }^{1}$ Orenburg State University, 460018, 13, Pobedy prospect, Orenburg, Russia \\ ${ }^{2}$ Federal Research Center of Biological Systems and Agrotechnologies of the Russian Academy of Sciences, 29, 9 Yanvarya., Orenburg \\ 460000, Russia
}

\begin{abstract}
Poultry farming is one of the most profitable and highly productive branches of agriculture. However, despite the achievements, there are many unresolved problems remaining in industrial poultry breeding. In particular, violating technological rules of feeding and housing and an amiss environmental state lead to deterioration of the immune system and development of a number of pathologies, which heavily reduces the productivity of this area of agriculture. Based on the above, much attention is focused on the search for drugs that would optimize the metabolism in the bird's organism, struggle with infectious agents, and increase the productivity of an organism. The study allows to comprehensively examine the properties of plants containing phytobiotic components and the use of modern technologies for producing and standardizing these components, when their experimental and manufacturing approbation lets widely apply plant extracts to animal feeding as dietary supplements of the latest generation based on raw materials of natural origin.
\end{abstract}

\section{Introduction}

Poultry farming is one of the most profitable and highly productive branches of agriculture. However, despite the achievements, there are many unresolved problems remaining in industrial poultry breeding. In particular, violating technological rules of feeding and housing and an amiss environmental state lead to deterioration of the immune system and development of a number of pathologies, which heavily reduces the productivity of this area of agriculture [1]. Based on the above, much attention is focused on the search for drugs that would optimize the metabolism in the bird's organism, struggle with infectious agents, and increase the productivity of an organism.

Feed antibiotics were used in all the sectors of livestock as such drugs at first [2]. However, the redundant use of them led to increased sustainability of micro-organisms, thereby excluding the positive effect of the drug. In addition, there were recorded cumulative and toxic effects [3], so, in recent years, many types of research have been devoted to medicinal plants that act as phytobiotics - biologically active substances with sufficiently high biological activity [4]. The most famous phytobiotic is the oak bark extract bearing a number of substances with anti-inflammatory, antimicrobial, and antiallergic activity [5-7]. The application of the oak bark extract helps prevent the development of a number of pathologies but the utilization of this substance in combination with antibacterial drugs and the effects of this combination on the body remain unexplored. In addition, the inhibiting influence of tetracycline on sensitivity to the quorum of Chromobacterium violaceum is known [9].

Considering the above, the purpose of our research was to study the combined action of the oak bark extract with chlortetracycline on hematological blood parameters of broiler chickens [11].

\section{Materials and Methods}

Experimental studies were carried out at the Center for collective use of scientific equipment of the Federal State Scientific Institution "Federal Research Center of Biological Systems and Agro-technologies of the Russian Academy of Sciences" (FSSI FRC BST RAS), the experiments were held in vivo (Gallus gallus). 120 heads of 7-day-old broiler chickens were selected for experiments ("Smena-8", four groups, $\mathrm{n}=30$ ). The control group received the main ration (MR), experimental group I - MR + the extract from Quercus cortex; experimental group II - MR + an antibiotic based on $20 \%$ chlortetracycline (dosed in accordance with recommendations of the manufacturer); experimental group III $-\mathrm{MR}+$ the antibiotic + the extract from Quercus cortex.

Bird treating and experimental procedures met the requirements and recommendations of Russian rules (order of the Ministry of the health of the USSR № 755

\footnotetext{
*E-mail: kwan111@yandex.ru, Tel: +7 (922) 548-56-57.
} 
of 12.08.1977) and "The Guide for the Care and Use of Laboratory Animals" (National Academy Press Washington, D.C. 1996). Watering was not regulated.

We used a mixture of compounds derived from the extract from Quercus cortex and chemically synthesized (Acros): propylresorcin; vanillin; coumarin; antiarol; scopoletin; coniferyl alcohol. The anti-QS-effect of this composition was confirmed by the strain of $\mathrm{C}$. violaceum CV026 with methods of diffusion into agar (qualitatively) and the method of serial dilutions in a liquid nutrient medium (quantitatively).

Chlortetracycline is the basis of a feed antibiotic (20\%) comprising approximately about $35-40 \%$ of proteins, vitamins (generally of group B, particularly $\mathrm{B} 12$ - not less than $8 \mathrm{mg}$ per $\mathrm{kg}$ of the product).

Blood samples were collected into vacuum tubes with the addition of an anticoagulant (EDTA-K3) for hematological analysis, for biochemical parameters into vacuum tubes with a clotting activator (thrombin). Hematological parameters were measured with an automatic hematological analyzer URIT-2900 Vet Plus ("URIT Medical Electronic Group Co., Ltd.", China).

Statistical processing of the data was carried out using the Statistica 10.0 software package. Data are presented as a mean $(\mathrm{M}) \pm$ the standard error of the mean (m). Significant results were considered at $\mathrm{P} \leq 0.05$.

\section{Results and Discussion}

The assessment of hematological parameters usually gives a picture of the reaction of the organism on the effect of a factor. According to the results of morphological and biochemical analyses of blood, one can get results on the physiological state of the animal, as well as conclude the usefulness of introducing a supplementary biological agent to the diet, in our case the antibiotic and the oak bark extract.

The analysis of morphological blood parameters of broiler chickens revealed changes in the experimental groups when compared to the control group (table 1). The red blood cell count is one of the most important indicators of the blood system. The study found that the addition of the antibiotic to the diet of agricultural birds led to a significant decline of erythrocytes by $17.9 \%$ ( $p \leq$ 0.05 ), and the co-administration of the oak bark extract and chlortetracycline - by $20.9 \%(p \leq 0.05)$ in comparison with the control group. A slight but statistically significant reduction of the red blood cell count in the experimental groups can be regarded as the development of erythropenia. A long introduction of the preparations can lead to iron deficiency anemia. In confirmation on the background of this, the same groups showed also a significant decrease of hemoglobin - by $16.1 \%$ and $23.4 \% \quad(\mathrm{p} \leq 0.05)$, respectively, and hematocrit was $18.6 \%$ and $23.8 \%$ lower in experimental groups II and III compared to the control, respectively.

Table 1. Morphological blood parameters of broiler chickens of the cross "Smena-8"

\begin{tabular}{lcccc}
\hline \multicolumn{1}{c}{ Parameter } & Control & Experimental I & Experimental II & Experimental III \\
\hline Hemoglobin, g/l & $131.3 \pm 9.54$ & $127.8 \pm 4.96$ & $110.2 \pm 2.03^{*}$ & $100.6 \pm 17.91^{*}$ \\
Hematocrit, \% & $23.1 \pm 1.91$ & $22.2 \pm 1.08$ & $18.8 \pm 0.33^{*}$ & $17.6 \pm 3.12^{*}$ \\
White blood cells, $10^{9} / 1$ & $19.9 \pm 6.21$ & $23.0 \pm 4.51^{*}$ & $17.2 \pm 1.15$ & $16.4 \pm 4.39^{*}$ \\
Red blood cells, $10^{12} / 1$ & $2.06 \pm 0.14$ & $1.97 \pm 0.07$ & $1.69 \pm 0.03^{*}$ & $1.63 \pm 0.29^{*}$ \\
Blood platelets, $10^{9} / 1$ & $67.5 \pm 7.35$ & $68.0 \pm 2.38$ & $61.2 \pm 1.39$ & $50.4 \pm 3.87^{* *}$ \\
\hline
\end{tabular}

$*-\mathrm{p} \leq 0.05 ; * *-\mathrm{p} \leq 0.01$

Table 2. The activity of enzymes in the serum of broiler chickens of the cross "Smena- 8 "

\begin{tabular}{lcccc}
\hline \multicolumn{1}{c}{ Parameter } & Control & Experimental I & Experimental II & Experimental III \\
\hline ALT, U/l & $3.80 \pm 0.76$ & $4.28 \pm 0.43$ & $5.18 \pm 0.58^{*}$ & $4.90 \pm 0.59$ \\
AST, U/1 & $228.8 \pm 31.8$ & $251.9 \pm 25.5$ & $252.6 \pm 25.8$ & $255.5 \pm 9.99$ \\
GGTP, U/1 & $16.5 \pm 1.04$ & $15.0 \pm 1.08$ & $17.0 \pm 1.18$ & $21.0 \pm 2.17^{*}$ \\
LDH, U/l & $14.3 \pm 3.68$ & $11.8 \pm 3.99$ & $16.8 \pm 5.19$ & $10.2 \pm 2.99^{*}$ \\
SOD, $\%$ & $879.8 \pm 54.2$ & $911.8 \pm 38.0$ & $934.3 \pm 94.0^{*}$ & $974.5 \pm 69.4^{*}$ \\
Catalase, $\mu$ mol & $1494.4 \pm 63.0$ & $1901.0 \pm 23.3^{*}$ & $1696.5 \pm 77.6$ & $1098.9 \pm 11.0^{*}$ \\
$\mathrm{H}_{2} \mathrm{O} / 1^{*}$ min & & & & \\
\hline
\end{tabular}

$*-\mathrm{p} \leq 0.05$

The birds of the first experimental group showed significant leukocytosis, which was $13.5 \%$ higher $(\mathrm{p} \leq$ 0.05 ) than that of the control group, it should be noted, however, that the level of leukocytes was within the norm. In experimental groups II and III, leukopenia was observed in comparison with the control group, the white blood cell count in the third group decreased by $13.6 \%$ (but the change was not statistically significant) and in the fourth group - by $17.6 \%(\mathrm{p} \leq 0.05)$. The platelet count revealed a significant decline for the combined introduction of the oak bark extract and the antibiotic to the diet by $25.3 \%(p \leq 0.05)$ compared to the control group while, in other experimental groups, the level of 
platelets in absolute values stayed at the same level and showed no significant changes.

Increased enzyme activity in serum is associated primarily with cytolysis and the release of enzymes from the damaged organs and tissues into the bloodstream. At that, the content and activity of an enzyme decrease in the damaged organ and increase in the serum (table 2). In our case, the values of alanine aminotransferase (ALT) and aspartate aminotransferase (AST) increased in the experimental groups on average by $11.2-26.6 \%$ and by $9.2-10.5 \%$, respectively, compared to the control group, but changes were not statistically significant, except experimental group II where a significant increase was observed for ALT by 1.4 times $(p \leq 0.05)$ compared to the control. Abundant sources of aspartate aminotransferase are the heart, the liver, skeletal muscles, nervous tissue, and the kidneys. The largest quantity of the enzyme alanine aminotransferase ALT is contained in the liver. Both of these enzymes in the body carry out processes of the intermolecular transfer of an amino group from donor gamma-amino acids to the acceptor alpha-ketonic acid without the intermediate formation of ammonium. Transamination plays a key role in the intermediate metabolism as it provides the synthesis and the destruction of some amino acids in the body.

The level of gamma-glutamyl transpeptidase (GGTP) also had a tendency to a significant increase in experimental group III by 1.3 times $(p \leq 0.05)$ on the background of a significant decline of lactic dehydrogenase $(\mathrm{LDH})$ by 1.4 times $(\mathrm{p} \leq 0.05)$ compared to the control. However, it should be noted there was recorded neither a critical boost nor a decrease of these enzymes in the serum. The introduction of the antibiotic with feed in group II led to a small significant increase of superoxide dismutase (SOD) by $5.83 \%(\mathrm{p} \leq 0.05)$ and the introduction of the composition of the substances in Group III - by $9.72 \%(\mathrm{p} \leq 0.05)$ in comparison with the control group. The catalase level significantly exceeded that of the control group in the 1 st experimental group by $21.4 \%$ ( $\mathrm{p} \leq 0.05)$ while the third experimental group revealed the opposite - a significant decrease by $26.5 \%$ $(\mathrm{p} \leq 0.05)$.

The analysis of biochemical parameters in the serum of broiler chickens revealed that the content of albumin was within the norm for chickens. It should be noted, however, that the experimental groups showed the albumin content was $6.99 \%, 5.00 \%$, and $7.64 \%$ higher (p $\leq 0.05$ ) than that in the control group, respectively. There were recorded significant differences from the control values $(\mathrm{p} \leq 0.05)$ in the third experimental group, where the antibiotic and the oak bark extract were utilized as an additive (table 3 ).

Table 3. Biochemical blood parameters of broiler chickens of the cross "Smena- 8 "

\begin{tabular}{lcccc}
\hline \multicolumn{1}{c}{ Parameter } & Control & Experimental I & Experimental II & Experimental III \\
\hline Glucose, mmol/l & $10.7 \pm 0.27$ & $11.4 \pm 0.10$ & $11.0 \pm 0.30$ & $10.4 \pm 0.24$ \\
Total protein g/l & $32.3 \pm 1.62$ & $33.9 \pm 0.29$ & $33.3 \pm 0.49$ & $34.2 \pm 1.45$ \\
Albumin, g/l & $13.3 \pm 0.75$ & $14.3 \pm 0.25$ & $14.0 \pm 0.63$ & $14.4 \pm 0.81^{*}$ \\
Conjugated bilirubin, & $0.41 \pm 0.02$ & $0.45 \pm 0.03$ & $0.42 \pm 0.03$ & $0.46 \pm 0.04$ \\
$\mu$ mol/l & $3.95 \pm 0.12$ & $3.96 \pm 0.10$ & $4.64 \pm 0.16$ & $4.01 \pm 0.09$ \\
Cholesterol, $\mathrm{mmol} / 1$ & $0.03 \pm 0.01$ & $0.09 \pm 0.02^{*}$ & $0.05 \pm 0.02^{*}$ & $0.06 \pm 0.02^{*}$ \\
Triglycerides, $\mathrm{mmol} / \mathrm{l}$ & $0.88 \pm 0.03$ & $0.93 \pm 0.03$ & $0.88 \pm 0.02$ & $0.92 \pm 0.05$ \\
Urea, mmol/l & $70.7 \pm 8.13$ & $71.1 \pm 4.48$ & $74.5 \pm 8.36^{*}$ & $79.7 \pm 10.6^{*}$ \\
Creatinine, $\mu \mathrm{mol} / \mathrm{l}$ & & & &
\end{tabular}

$*$ - $\mathrm{p} \leq 0.05$

Triglycerides are essential energy part of lipids that are actively involved in the metabolism of fat-soluble vitamins, thus ensuring the full functioning of the organism reactions. The studied additives contributed to a significant increase in all experimental groups by 3.0 times, 1.7 times, and 2 times $(\mathrm{p} \leq 0.05)$ compared to the control, respectively. It should be noted that the creatinine level also significantly raised in experimental groups II and III by $5.1 \%$ and $11.3 \%(\mathrm{p} \leq 0.05)$ in comparison with the control group.

For the normal vital activity of an organism, inorganic components are also important besides organic substances in an organism's composition. We studied several indicators of the mineral metabolism that make it possible to judge about the functional status of systems and organs of bird's body (table 4).

Table 4. Analysis of the serum of broiler chickens on macro- and microelements

\begin{tabular}{lllll}
\hline Parameter & Control & Experimental I & Experimental II & Experimental III \\
\hline $\mathrm{Ca}, \mathrm{mmol} / \mathrm{l}$ & $2.53 \pm 0.06$ & $2.7 \pm 0.04$ & $2.51 \pm 0.05$ & $2.45 \pm 0.06$ \\
$\mathrm{P}, \mathrm{mmol} / \mathrm{l}$ & $2.07 \pm 0.28$ & $1.75 \pm 0.17 *$ & $2.24 \pm 0.57$ & $2.83 \pm 0.85^{*}$ \\
$\mathrm{Fe}, \mu \mathrm{mol} / \mathrm{l}$ & $28.8 \pm 0.80$ & $32.8 \pm 5.07$ & $35.7 \pm 4.44$ & $33.1 \pm 10.5$ \\
$\mathrm{Mg}, \mathrm{mmol} / \mathrm{l}$ & $1.29 \pm 0.05$ & $1.30 \pm 0.02$ & $1.29 \pm 0.06$ & $1.21 \pm 0.06$ \\
\hline
\end{tabular}

$*-\mathrm{p} \leq 0.05 ; * *-\mathrm{p} \leq 0.01$ 
The analysis of biochemical parameters in the serum of broiler chickens revealed increased levels of iron in the serum of the experimental groups, which amounted from $28.8 \mu \mathrm{mol} / 1$ to $35.7 \mu \mathrm{mol} / 1$ in absolute values, although the changes were insignificant, as a consequence, they indicated intensifying the function of hematopoiesis.

We found that the chickens of the experimental groups that received only the oak bark extract were characterized with a significant decline of phosphorus in blood by $15.5 \%(p<0.05)$, although this parameter was within the norm. Group III showed a significant increase of phosphorus by 26.9\% ( $p<0.05)$. The content of calcium in experimental groups was without any visible significant changes. Magnesium is a trace element that participates in the work of very many enzymes in the body, takes part in the nerve-muscle excitation, and is closely associated with the metabolism of calcium and phosphorus. Analyzing our data, it can be noted that the use of the antibiotic and the oak bark extract did not influence the content of magnesium in the serum of chickens. All parameters were within the norm and had no statistically significant differences $(\mathrm{p}<0.05)$.

\section{Conclusions}

1. This study allows to comprehensively examine the properties of plants containing phytobiotic components and the use of modern technologies for producing and standardizing these components.

2. Their experimental and manufacturing approbation lets widely apply plant extracts to animal feeding as dietary supplements of the latest generation based on raw materials of natural origin.

\section{Acknowledgement}

The research was conducted with financial support from the Russian Science Foundation (Grant \#16-16-10048).

\section{References}

1. V.I. Fisinin, A.S. Ushakov, G.K. Duskaev, N.M. Kazachkova, B.S. Nurzhanov, Sh.G. Rakhmatullin, G.I. Levakhin, Sel'skokhozyaistvennaya Biologiya 53(2), 385-392 (2018)

2. R.I. Castillo-Lypez, E.P. Gutiérrez-Grijalva, N. Leyva-López, L.X. López-Martínez, J.B. Heredia, J. Anim. Plant Sci. 27(2), 349-359 (2017)

3. G.K. Duskaev, N.M. Kazachkova, A.S. Ushakov, B.S. Nurzhanov, A.F. Rysaev, Veterinary World 11(2), 235-239 (2018) doi: 10.14202/vetworld.2018.235-239

4. M.M. Gheisar, I.H. Kim, Ital. J. Anim. Sci. 17(1), 92-99 (2018) doi: 10.1080/1828051X.2017.1350120

5. D.G. Deryabin, A.A. Tolmacheva, Molecules 20(9), 17093-17108 (2015)

6. H. Hao, G. Cheng, Z. Iqbal, X. Ai, H.I. Hussain, L. Huang, M. Dai, Y. Wang, Z. Liu, Z. Yuan, Front.
Microbiol.
$5, \quad 288$
(2014)
doi:

10.3389/fmicb.2014.00288

7. O. Kvan, I. Gavrish, S. Lebedev, A. Korotkova, E. Miroshnikova, A. Bykov, V. Serdaeva, N. Davydova, Environ. Sci. Pollut. Res. 25(3), 21752183 (2018)

8. K.Kh. Farnieva Effektivnost' introduktsii i perspektivy ispol'zovaniya ekhinatsei purpurnoi (Echinacea purpurea (L.) Moench) v usloviyakh RSO-Alaniya. Avtoreferat kandidatskoi dissertatsii [Introduction and use of Echinacea purpurea (L.) Moench in Alania. Ph.D. Thesis] (Vladikavkaz, 2015)

9. D.G. Deryabin, K.S. Inchagova, Microbiology (Mikrobiologiya) 87(1), 3-11 (2018)

10. E.A. Sizova, S.A. Miroshnikov, S.V. Lebedev, Yu.I. Levakhin, I.A. Babicheva, V.I. Kosilov, Sel'skokhozyaistvennaya Biologiya 53(2), 393-403 (2018)

11. V.A. Bagirov, G.K. Duskaev, N.M. Kazachkova, Sh.G. Rakhmatullin, E.V. Yausheva, D.B. Kosyan, Sh.A. Makaev, Kh.B. Dusaeva, Sel'skokhozyaistvennaya Biologiya 53(4), 799-810 (2018) 